This text is a pre-print. Paging and layout may differ from the final published version. For the purpose of citation, please refer to the publisher's version: Julio Escalona, 'The Early Middle Ages: A Scale-Based Approach', in Escalona, J. and Reynolds, A. (eds), Scale and Scale Change in the Early Middle Ages: Exploring landscape, local society and the world beyond (Turnhout: Brepols, 2011) 9-30

\title{
The EARly MidDle AgeS: A SCALE-BASED APPROACH ${ }^{*}$
}

\author{
Julio Escalona
}

[Scale] is, I would argue, the fundamental conceptual problem in ecology, if not in all of science. $^{1}$

$\mathrm{L}$

evin's emphatic assessment of the importance of scale in ecology - like similar ones made from other scientific fields - illustrates one side of a repeated paradox: while the highly abstract notion of scale is fundamental to almost all disciplines, it is often taken for granted and rarely explicitly addressed in itself as a topic worthy of consideration. Even today, after more than two decades of increasing concern about scale and scale-related issues, the issue

\footnotetext{
*Preliminary versions of this text were used as a working paper in the FES Project sessions, and were discussed at different stages by the project members. I owe them all recognition for their input, as well as to Dr Richard Reece, who attended the spring 2007 plenary meeting at Woolstone (Oxon.). The main ideas were presented in 2006 to the members of the Globalization Discussion Group at the Instituto de Historia (CSIC). I particularly thank Antonio Lafuente for his remarks on post-modernism and for leading me back to the works of Lefebvre and the radical geographers of the 1970s. More developed versions were presented in 2008 at the Arab Studies Seminar (Instituto de Historia, CSIC) and at the Universidad de Salamanca, and in 2009 at the Escuela Española de Historia y Arqueología en Roma (CSIC). I thank all those who attended and took part in the discussions for their remarks, which have been a great help in refining the text. Especial thanks are due to my co-editor, Andrew Reynolds, who shares my concern for theoretical approaches and the need for interdisciplinary convergence, for enlightening conversations, and a lot of encouragement. As always, Wendy Davies's comments have been extraordinarily helpful and thought provoking. Despite such a long list of acknowledgements, all flaws and errors in this text are my exclusive responsibility.

${ }^{1}$ Simon A. Levin, 'The Problem of Pattern and Scale in Ecology', Ecology, 73 (1992), 194367 (p. 1944).
} 
remains very much a matter for the initiated when it is not simply unnoticed. The situation, however, is most diverse even within the social sciences. To name only three examples, geographers have long been familiar with scale, to the point that geographical scale is often understood by them as the quintessential form of scale. In archaeology, instead, the matter is relatively new, although it seems to grow rapidly, especially in connection with the increasing importance of GIS. Most historians, finally, seem to live happy lives with virtually no regard to scale. Historical literature is, of course, full of interesting debates on issues which are ultimately scale matters; but more often than not, they are not recognized as belonging to that theoretical scenario.

If we stray from the abstract path of mathematics, ecology is arguably the discipline in which scale has received most attention and reached the most refined theoretical formulations. It is nonetheless interesting to us because of the growing influence of ecological approaches in the social sciences. ${ }^{2}$ A recent survey on a selection of ecology journals showed that the use of scale-related words increased dramatically during the second half of the twentieth century, with a steep take-off in the 1960 s, followed by steady growth up to the present. ${ }^{3}$ Social and historical sciences largely seem to match this pattern, although the take-off point may differ among disciplines and, unsurprisingly, history remains much detached from scalerelated terminology, as it is from theory in general.

Any comprehensive notion of scale needs to take into account the fact that the term encompasses at least two different meanings stemming from a major epistemological issue: the scientist's relationship to his object. The nomenclature varies among one field and/or author to another, but the distinction does not seem to be discipline dependent. Hence, Sayre distinguishes 'the epistemological and the ontological moments of scale, ${ }^{4}$ while Wu and Li use the more user-friendly

\footnotetext{
${ }^{2}$ Clark Gibson, Elinor Ostrom, and Toh-Kyeong Ahn, IHDP Working Paper No. 1: Scaling Issues in the Social Sciences, International Hum an Dimensions Programme Global Environmental Change (Bonn, 1998), section 2.1, <http://www.ihdp.uni-bonn.de/html/publications/working paper/wp01.htm > [accessed 26 July 2010].

${ }^{3}$ Jianguo Wu and Ye Qi, 'Dealing with Scale in Landscape Analysis: An Overview', Geographic Information Sciences, 6 (2000), 1-5, fig. 1.1 discusses the survey in detail. A more concise summary in Jianguo Wu and Harbin Li, 'Concepts of Scale and Scaling', in Scaling and Uncertainty Analysis in Ecology: Methods and Applications, ed. by Jiangou Wu and others (Dordrecht: Springer, 2006), pp. 3-15.

${ }^{4}$ Nathan F. Sayre, 'Geographical Scale: Parallels and Potential for Integration', Progress in Human Geography, 29 (2005), 276-90 (p. 278).
} 
terms observational scale and intrinsic scale, ${ }^{5}$ which I will adopt hereafter. Not everyone draws such a distinction, though. Theoretical and methodological overviews of scale tend to consider them together while, tellingly, practical applications of scale concepts normally focus upon one or the other. ${ }^{6}$

\section{Observational Scale (Scale as the Observer's Strategy)}

Scale is commonly placed at the centre of the observer-to-object relationship, as a crucial factor of any research strategy. ${ }^{7}$ The sense an observer makes of an object is determined by observational scale, which involves factors such as extent (the boundaries of the observations beyond which no information is collected), grain (the minimum size unit within which information can be collected for a given scale), and others. ${ }^{8}$ Observational scale is, then, 'an attribute of how one observes something rather than of the thing observed'. ${ }^{9}$ It works within the twofold dimensionality of space and time, since observations are rarely just spatial or temporal, but more often involve elements of both, even if imbalanced.

In ecological literature spatial and temporal scales are commonly linked to the recognition of pattern and process. Thus, spatial scale is the key factor in recognizing patterns, while temporal scale works similarly for processes. ${ }^{10}$ Phenomena detected at one scale of observation may be invisible at another. ${ }^{11}$ In geography, observational scale lies at the core of the notion of cartographic scale, i.e. the relationship between the real world and the phenomena represented on a map, determining which aspects of the former will or will not be mapped. In general, for all social sciences, observational scale is an especially important methodological

${ }^{5} \mathrm{Wu}$ and $\mathrm{Li}$, 'Concepts of Scale', p. 7.

${ }^{6}$ John A. Wiens, 'Spatial Scaling in Ecology', Functional Ecology, 3 (1989), 385-97; Levin, 'The Problem of Pattern and Scale'; Gibson, Ostrom, and Ahn, Scaling Issues; Wu and Qi, 'Dealing with Scale'; Wu and Li, 'Concepts of Scale'.

${ }^{7}$ Further specification may lead to subdivisions within the same basic category. See Wu and Li, 'Concepts of Scale', p. 7.

${ }^{8}$ The components of scale are numbered, named, and defined differently from one author to another. Compare, for instance, Gibson, Ostrom, and Ahn, Scaling Issues, section 1.1; Wiens, 'Spatial Scaling'; or Wu and Li, 'Concepts of Scale'.

${ }^{9}$ Sayre, 'Geographical Scale', p. 280.

${ }^{10}$ Levin, 'The Problem of Pattern and Scale', p. 1992.

${ }^{11}$ Wiens, 'Spatial Scaling'. 
issue when selective processes of data collection are involved. In archaeology, the boom of surface survey in the 1980s and 1990s triggered much discussion about the methodology of survey design, a great part of which essentially dealt with observational scale and its components. The great impact of factors such as extent, grid-size, and coverage on the costs of field survey was no small reason for paying them attention. Since the 1990s, the popularization of tele-detection and GIS gave further impulse to scale issues across sciences such as ecology, geography, and, of course, archaeology. When working with those technologies, observational scale is a critical choice. Not only the representation and analysis of collected data are affected. It also determines the necessary hardware performance and the basic cartography and/or satellite or aerial imagery needed; in other words, it affects a great deal of the research's budget. Not surprisingly, this shows in the growing number of titles devoted to GIS, sampling, and modelling in archaeology: when scale is explicitly addressed, it is most frequently observational scale that is under scrutiny. ${ }^{12}$

Observational scale has profound methodological implications in the social sciences. Most social sciences defined themselves in the late nineteenth and early twentieth century by developing specific epistemologies in parallel with the creation of their respective academic spaces and identities. A major divide opened between nomothetic-oriented sciences, which sought to disentangle the rules governing reality, to recognize pattern and process and formulate them in as 'objective' a manner as possible, and ideographic-oriented disciplines, which saw the world as a succession of contingent events open not to formulation, but to description and narration, of which no pattern or process could be inferred that was not dependent on the contingency of individual cases. ${ }^{13}$ In principle, this

\footnotetext{
${ }^{12}$ Ezra B. W. Zubrow, 'Contemplating Space: A Commentary on Theory', in Interpreting Space: GIS and Archaeology, ed. by Kathleen M. S. Allen, Stanton W. Green, and Ezra B. W. Zubrow (London: Taylor and Francis, 1990), pp. 67-79; Kathleen M. S. Allen, 'Considerations of Scale in Modeling Settlement Patterns Using GIS: An Iroquois Example', in Practical Applications of GIS for Archaeologists: A Predictive Modeling Toolkit, ed. by Konnie L. Wescott and R. Joe Brandon (London: Taylor and Francis, 2000), pp. 101-12; and especially Exploring the Role of Analytical Scale in Archaeological Interpretation, ed. by James R. Mathieu and Rachel E. Scott, British Archaeological Reports, International Series, 1261 (Oxford: Barhedges, 2004), and Confronting Scale in Archaeology: Issues of Theory and Practice, ed. by M. Gary Lock and Brian L. Molyneaux (New York: Springer, 2006).

${ }^{13}$ Immanuel Wallerstein, 'The Time of Space and the Space of Time: The Future of Social Science', Political Geography, 17 (1998), 71-82, has brilliantly shown how diverging epistemological orientations led to each discipline's having an entirely different notion of 'tem poral scale', and the consequences thereof for their mutual exchanges.
} 
could make certain fields (political science, economy, sociology, archaeology) more prone than others, like anthropology and, above all, history, to adopt scale as a key analytical factor. However, disciplinary boundaries are more a factor of academic politics than of science itself and a century-long history of overlapping research and mutual influences has made interdisciplinary differences less critical, showing that nomothetic and ideographic epistemological approaches have coexisted to some extent in all social sciences. This shows eloquently in the distinction between 'macro' and 'micro' analysis, i.e. research oriented to the medium- or large-scale processes and research devoted to describe the unrepeatable complexity of individual behaviour. In economy, 'macro' and 'micro' analyses seem to belong to separate worlds, ${ }^{14}$ just as 'macro' and 'micro' geographical studies do. ${ }^{15}$ Ultimately, it seems that scientists working on the same scale of human phenomena - whether economists, geographers, or sociologists - tend to recognize very much the same things, and that the methods and theories of 'macro' studies are easier to share among disciplines than with those of 'micro' studies in each of their own fields.

\section{Intrinsic Scale (Scale at which Patterns or Processes Operate)}

The very idea that patterns and processes become visible or invisible depending on the observational scale adopted is a tacit statement of intrinsic scale: that patterns and processes in the real world operate at certain scales, and that scale is a crucial element determining their structure and workings. This notion that structure exists in the real world, and that scale is a crucial component of it was rarely questioned by mid-twentieth-century science. By then scale analysis had begun to achieve some relevance in social sciences such as sociology, economy or political science, which were committed to describe their objects in terms of patterns, processes and regularities. In the late twentieth century, though, postmodernism sent a wave of criticism directly targeting the epistemological foundations of modern science. The observer-to-object relationship was re-problematized by stressing the observer's role in constructing a meaningful image of the latter. Consequently, scale would not be so much a component of reality's structure as a cognitive resource deployed by the human observer in trying to

\footnotetext{
${ }^{14}$ Gibson, Ostrom, and Ahn, Scaling Issues, section 2.3.

${ }^{15}$ Mary K. Watson, 'The Scale Problem in Human Geography', Geografiska Annaler: Series B, Human Geography, 60 (1978), 36-47.
} 
make sense of the world observed. In other words, a structure of the human mind, rather than of reality.

After the so-called 'post-modernist turn' scientists did not give up all hopes of making sense of the world, but they became more aware of the constraints imposed on the observer by his mental and social background, theoretical orientation, and methods. Different disciplines have dealt differently with the impact of post-modernism upon their epistemological roots, but in general there is a greater awareness of the importance of individual perception and subjectivism in the process of creation of scientific knowledge. Recent commentators, for example, will qualify the objectivist notion of scale by arguing that scale results from the interaction between the observing mind's analytical tools and the intrinsic scale of the observed phenomena. ${ }^{16}$ This is both a relativization of the previously unproblematized observer-to-object relationship and an acknowledgement that scale exists at both ends of the chain. Moreover, the notion of scale mismatch has been developed to describe cases in which a human agent - whether a scientific observer or a policy maker - fails to operate at the same scale as the targeted processes. ${ }^{17}$

\section{Measure and Hierarchy}

As the word becomes increasingly fashionable, the claim that scale is becoming a sort of buzzword in several disciplines seems to gain grounds. ${ }^{18}$ In practice, its use is often riddled with theoretical ambiguity and confusion, ranging from abstract formulations to coarser everyday uses. Without close examination, it is often difficult to grasp a clear idea of what one particular author means by scale, and classifications of types of scale are even more diverse, for they normally include custom-made divisions especially adapted to specific disciplines. ${ }^{19}$ Perhaps most

\footnotetext{
${ }^{16} \mathrm{Wu}$ and Li, 'Concepts of Scale', p. 7; Sayre, 'Geographical Scale', p. 280.

${ }^{17}$ Graeme S. Cumming, David H. M. Cumming, and Charles L. Redman, 'Scale Mismatches in Social-Ecological Systems: Causes, Consequences, and Solutions', Ecology and Society, 11 (2006), 14, <http://www.ecologyandsociety.org/vol11/iss1/art14/> [accessed 26 July 2010].

${ }^{18}$ Wiens, 'Spatial Scaling', p. 385; Neil Brenner, 'The Limits to Scale? Methodological Reflections on Scalar Structuration', Progress in Human Geography, 25.4 (2001), 591-614 (p. 591); Wu and Li, 'Concepts of Scale', p. 4.

${ }^{19}$ Compare the ones in the aforecited ecological literature with geographical classifications, such as Gary M. Pereira, 'A Typology of Spatial and Temporal Scale Relations', Geographical Analysis, 34 (2002), 21-33 (p. 23), or Neil Smith, 'Scale', in The Dictionary of Human Geography,
} 
extended is the notion of scale as measure, for instance: 'Scale is the dimension used in any effort to measure a phenomenon. The three most obvious types of scales used by scientists are space, time, and quantity. ${ }^{.20}$ In ecology and social sciences, this normally means spatial extent, temporal range, and/or simply size. ${ }^{21}$ Some of the earliest explicit discussions of scale and social relations in sociology, for example, were built upon the notion of scale as demographic size, ${ }^{22}$ a usage that has been recently rehearsed by Bodley: 'Scale refers to the absolute size of populations, economic enterprises, markets, armies, cities or anything that affects the well-being of people. ${ }^{23}$

More theory-focussed approaches tend to characterize scale as organizational complexity. ${ }^{24}$ In hierarchy theory, ${ }^{25}$ scale is an important tool for dealing with complexity. Complex systems - or hierarchies - are conceived as ordered in hierarchical levels, each defined by its constituent entities and their mutual relationships, as well as their relationships with the upper and lower levels. In the simplest possible approach, organizational levels can be distinguished by several criteria, of which the most obvious is that higher levels often work at greater spatial and temporal scales, and they contain or are made of lower ones, to whom

ed. by Ron J. Johnston and others, 4th edn (Oxford: Blackwell, 2000), pp. 724-27. See also G. Darrel Jenerette and Jianguo Wu, 'On the Definitions of Scale', Bulletin of the Ecological Society of America, 81 (2000), 104-05.

${ }^{20}$ Gibson, Strom, and Ahn, Scaling Issues, preface; Brenner, 'The Limits to Scale?'; Sayre, 'Geographical Scale'.

${ }^{21}$ Max Rietkerk and others, 'Editorial: The Ecology of Scale', Ecological Modelling, 149 (2002), 1-4 (p. 2): 'scale relates to the temporal and spatial dimensions at which phenomena are observed'. See also Wu and Li, 'Concepts of Scale', p. 3.

${ }^{22}$ See Bruce H. Mayhew, 'System Size and Ruling Elites', American Sociological Review, 38 (1973), 468-75; Gerald D. Berreman, 'Scale and Social Relations', Current Anthropology, 19 (1978), 225-45 and the collected essays in Scale and Social Organization, ed. by Fredrik Barth (Oslo: Universitetsforlaget, 1978), as well as the ensuing debate: Anthony Leeds, 'On Scale', Current Anthropology, 19 (1978), 624-25; Gerald Weiss, 'Scale and Social Organization', American Anthropologist, 82 (1980), 135-37, and Ralph Thomlinson, 'Scale and Social Organization', The American Journal of Sociology, 86 (1981), 924-26.

${ }^{23}$ John Bodley, The Power of Scale: A Global History Approach (Armonk: Sharpe, 2003), p. 5.

${ }^{24}$ Levin, 'The Problem of Pattern and Scale', p. 1944.

${ }^{25}$ An overview in Valery Ahl and Timothy F. H. Allen, Hierarchy Theory: A Vision, Vocabulary and Epistemology (New York: Columbia University Press, 1996). See also Timothy F. H. Allen and others, 'The Problem of Scaling in Ecology', Evolutionary Trends in Plants, 7 (1994), 3-8. 
they operate as the 'context'. Definitions and applications of scale within hierarchy theory are easier to find in recent ecological research, much less so in the social sciences, although sociologists and political scientists have engaged with it, especially over computer-based simulations. ${ }^{26}$ It is long recognized that levels in complex social systems do not form an orderly pyramid, but rather a network of partially concurrent, partially divergent processes: political or governmental divisions often do not have matching social stratifications or trade networks, and so on. In the end, no single level alone is correct for the study of complex hierarchical systems: all levels - and the connections between them - are relevant. ${ }^{27}$ It is thus necessary to consider the total hierarchical span (how many levels are there in a system and which position a certain level occupies), the relationships between levels and between units within a level, and the properties they generate. Consequently, complex systems require a multi-scale approach in comparing one level to another, one system to another, or one phase to another in a system's evolution. ${ }^{28}$

The related issue of thresholds or scale-breaks is slippery ground. Just as scale is often seen as size, scale-breaks tend to be understood in quantitative, rather than qualitative terms. A widespread practice is to express them mathematically as orders of magnitude, or powers, meaning that they do not grow arithmetically, but geometrically, so they must be represented on a logarithmic, rather than linear scale. The most common choice is that of a decimal logarithmic scale, in which every step results from multiplying by ten the previous one. Powers of ten have been used, for example, to convert the Bogardus Social Distance Scale into a quantifiable variable ${ }^{29}$ and more recently by Bodley to represent an evolutionary spectrum of forms of social organization. ${ }^{30}$ However, the crucial issue is not so much

\footnotetext{
${ }^{26}$ For instance, Paul B. Roscoe, 'Practice and Political Centralisation: A New Approach to Political Evolution', Current Anthropology, 34 (1993), 111-40, and Eric Alden Smith and JungKyoo Choi, 'The Emergence of Inequality in Small-Scale Societies: Simple Scenarios and AgentBased Simulations', in Modeling Socioecological Systems, ed. by Timothy A. Kohler and Sander E. Van der Leeuw (Santa Fe: School of American Research, forthcoming).

${ }^{27}$ Gibson, Ostrom, and Ahn, Scaling Issues, section 1.1.

${ }^{28}$ Levin, 'The Problem of Pattern and Scale', p. 1947.

29 Philip J. Ethington, 'The Intellectual Construction of "Social Distance": Toward a Recovery of Georg Simmel's Social Geometry', Cybergeo: Epistemologie, Histoire, Didactique, article 30, published online 16 September 1997, modified 21 June 2007, <http://www.cybergeo.eu/ index227.html> [accessed 30 September 2008].

${ }^{30}$ Bodley, The Power of Scale, p. 56, fig. 5. Powers of 10 are, of course, an intuitive approach
} 
quantification as it is the emergence of qualitatively distinctive properties. For example, a kingdom's territorial expansion may be just a matter of quantitative growth. It becomes scale change if and when the expansion generates systemic reorganization. In other words, scale-breaks are a matter of quality and relation, not just of quantity.

\section{Agency: The Social Production of Scale and Time Scales}

The notion of scale as organizational complexity within the scope of hierarchy theory is more widespread in ecology than in the social sciences, where - for instance, in geography - the relational dimension of scale is more emphasized than its connection with hierarchical systems. ${ }^{31}$ This 'softer' side of the notion of intrinsic scale as relation seems to be perceived as more suitable to the study of human societies, especially in those disciplines where post-modernism made a deeper epistemological impact. The human factor makes, of course, a major difference between ecology and the social sciences. In ecology, the emphasis on the observer's experience, characteristic of late twentieth-century subjectivism, brought to the frontline the cognitive problems associated with observational scale while keeping a sharp distinction between the observed ecological systems and the human observer. By contrast, in the social sciences, the problem of human observation is present at both ends: the observer and the thing observed. There is a human mind trying to make sense of the world, but the observed phenomena are basically human actors with human minds, and with their own cultural perceptions of social relationships, space, time, and - explicitly or not - scale.

Probably the most exciting developments along this line come from the field of Political Geography. Building on Henri Lefebvre's influential The Production of Space, ${ }^{32}$ the so-called 'radical geographers' of the 1970 s and 1980 s contended

to size differences. The method was made popular by Charles and Ray Eames's famous movie of scientific divulgation Powers of Ten (1977), in which zooming in and out by 10 in each step makes clear how the reality's appearance changes with scale. Of course, this is a paramount example of observational, not intrinsic scale, and it must be noted that, while powers of 10 are an intuitive choice for a modern western mind, there is no theoretical or empirical reason why 10 should be better than 4, 2, or 7 in describing scale-breaks in real-world phenomena.

${ }^{31}$ Richard Howitt, 'Scale', in A Companion to Political Geography, ed. by John Agnew, Katharyne Mitchell, and Gearóid Ó Tuathail (Oxford: Blackwell, 2007), pp. 132-57.

${ }^{32}$ Henri Lefebvre, The Production of Space (Oxford: Blackwell, 1991), original French text published in 1974. 
that human spatiality was not based on given, stable structures, but on categories created and modified by human actors in the course of social processes of interaction, competition, or conflict. ${ }^{33}$ This opened a door to the introduction of the sociological/political notion of practice, as developed by authors such as A. Giddens and P. Bourdieu, ${ }^{34}$ in an effort to conceptualize the spatial dimensions of power relationships. Practice theory is of great help in bridging the individual and the systemic. It reshapes structure not as a given, but as the result of social interaction. Scalar structuration, therefore, is no longer seen as the sort of invisible engine determining individual behaviour of functionalist/materialistic approaches, but rather as both a social construct and a social resource that actors may use, transform, and compete for. ${ }^{35}$ It is individual perception and agency that create the dynamic sets of shared notions, visions of reality, practices and institutions that are the building blocks of social structures.

The notion of the social production of space amongst political geographers has evolved more recently towards the social — and/or political - production of scale, a term that underpins human agency as a key factor in scalar structuration. ${ }^{36}$ Especially interesting is the increasingly fashionable concept of jumping scales,

${ }^{33}$ On Lefebvre's influence on later scale-focussed developments, see Neil Brenner, 'The Urban Question as a Scale Question: Reflections on Henri Lefebvre's Urban Theory and the Politics of Scale,' International Journal of Urban and Regional Research, 24 (2000), 361-78.

${ }^{34}$ Anthony Giddens, Studies in Social and Political Theory (London: Hutchinson, 1977); Giddens, Central Problems in Social Theory: Action, Structure and Contradiction in Social Analysis (Houndmills: Macmillan Education, 1979); Pierre Bourdieu, Esquisse d'une théorie de la pratique (Genève: Droz, 1972); Bourdieu, Le Sens pratique (Paris: Minuit, 1980).

35 John Robb, 'Agency', in Archaeology: The Key Concepts, ed. by Colin Renfrew and Paul Bahn (London: Routledge, 2005), pp. 3-7; Cox, 'Representation and Power'.

${ }^{36}$ Kevin R. Cox, 'Spaces of Dependence, Spaces of Engagement and the Politics of Scale, or Looking for Local Politics', Political Geography, 17 (1998), 1-23; Cox, 'Representation and Power in the Politics of Scale', Political Geography, 17 (1998), 41-44; Katherine T. Jones, 'Scale as Epistemology', Political Geography, 17 (1998), 25-28; Dennis R. Judd, 'The Case of the Missing Scales: A Commentary on Cox', Political Geography, 17 (1998), 29-34; Sally A. Marston, 'The Social Construction of Scale', Progress in Human Geography, 24 (2000), 219-42; Brenner, 'The Limits to Scale?'. Agency-centred approaches in geography and political science have had a feedback impact on ecology: ecologists with a greater interest in human agency within ecological systems have been quicker to incorporate social notions that bring their research up the alley of social scientists. See, for example, Louis Lebel, Po Garden, and Masao Imamura, 'The Politics of Scale, Position, and Place in the Governance of Water Resources in the Mekong Region', Ecology and Society, 10.2 (2005), 18, <http://www.ecologyandsociety.org/vol10/ iss2/art18/> [accessed 26 July 2010]. 
used to describe how actors operating at a given scale are able to connect to processes operating at another - higher or lower - scale in order to reinforce their claims within their own context (for instance, claims from local environmentalist associations can gain strength by showing their objectives to be not just local but regional, national, or global, and by using resources - material or ideological available at those scales).$^{37}$ This implies a certain degree of awareness of the multiscalar nature of society, and the ability to use it as a resource in social competition. It also depends, of course, on how open those scales are to bottom-up or top-down action, and such action does not need to always be a defensive strategy or resistance from the local towards the global, as it is often conceived..$^{38} \mathrm{~A}$ worldwide communication facility like the Internet can be used by international institutions, national governmental agencies, local administrations, global environmentalist groups, or individuals for their respective aims, at their respective scales.

This brings back the issue of observational scale, but this time on the actors' side, rather than the observer's. Conscious response to scale change cannot happen if human actors are unable to perceive it, which implies some degree of concordance between the spatial-temporal scales of processes and the actors' observational position. Although spatial scale tends to grab the headlines, time scale is a hugely important factor, which has been the object of a growing body of research in the last two decades, mainly in sociology ${ }^{39}$ but increasingly so in archaeology too. ${ }^{40}$ Time scale has a great bearing on pattern-construction. For

37 Cox, 'Representation and Power'; Saskia Sassen, Territory, Authority, Rights: From Medieval to Global Assemblages (Princeton: Princeton University Press, 2006), esp. pp. 365-75.

38 Thomas D. Hall, 'Frontiers, Ethnogenesis and World-Systems: Rethinking the Theories', in A World-Systems Reader: New Perspectives on Gender, Urbanism, Cultures, Indigenous Peoples and Ecology, ed. by Thomas D. Hall (Oxford: Rowman and Littlefield, 2000), pp. 237-70.

${ }^{39}$ Werner Bergmann, 'The Problem of Time in Sociology: An Overview of the Literature on the State of Theory and Research on the "Sociology of Time", 1900-82', Time and Society, 1 (1992), 81-134; Helga Nowotny, 'Time and Social Theory: Towards a Social Theory of Time', Time and Society, 1.3 (1992), 421-54.

${ }^{40}$ Geoff Bailey, 'Time Perspectives, Palimpsests and the Archaeology of Time', Journal of Anthropological Archaeology, 26 (2007), 198-223; Alasdair Whittle and Alex Bayliss, 'The Times of Their Lives: From Chronological Precision to Kinds of History and Change', Cambridge Archaeological Journal, 17 (2007), 21-28; Chris Gosden and Karola Kirsanow, 'Timescales', in Confronting Scale in Archaeology: Issues of Theory and Practice, ed. by Gary Lock and Brian L. Molyneaux (New York: Springer, 2006), pp. 27-37; Gavin Lucas, 'Time and the Archaeological Event', Cambridge Archaeological Journal, 18 (2008), 95-65; Ruth M. Van Dyke, 'Tem poral Scale 
example, the development and renegotiation of shared values, notions, and memory in oral - or predominantly oral - contexts works at a number of temporal scales. Tales and stories may be preserved for many generations, constituting the backbone of established views of the past; instead, the possibility of finding witnesses of past events is clearly limited by biological factors, like life expectancy and the pace of generation replacement, etc. Likewise, informal social interactions as much as formal, ritualized events play a major role in the making and the cultural transmission of social memory ${ }^{41}$ and many such activities are ordered within time scales (daily, weekly, seasonally, yearly, etc.) which, by cyclic repetition, tend to yield a picture of steady flow and timelessness to contingent social ordering. The perception of time moulded by those events is clearly very different from the individual perception of acute changes happening within the span of one generation, like war, natural disasters, economic crisis, military conquest, or, say, the pioneering colonization of desert lands.

If time scales affect perception, they must affect agency too. Changes taking place over a very long time span, like climatic change, for instance, are likely to go unnoticed by actors without access to long-term climatic records. However, being unable to grasp the intrinsic scale of historical processes does not mean that people will stay disconnected from them. Large-scale articulations and processes do not belong to a higher, placeless sphere; they manifest themselves locally and produce local impacts, even if driven by overly supra-local forces. Local actors may be unaware of the large-scale dimensions of processes affecting them, or they may simply be unable to react at a similar scale, but they may well respond to the partial local impacts of such processes. For example, peasant communities may not recognize long-term climatic change, but they may well perceive and react to partial specific manifestations of the broader, unrecognized process. The members of aboriginal communities may be or may not be aware of the global economic forces that fuel large-scale deforestation in Amazonia, but they still resist the local manifestations thereof that affect them directly. These are cases of scale-mismatch, when actors react only to the local manifestations of larger scale processes, very much like individual national governments striving to counteract separately their share of the 2008 global financial crisis.

and Qualitative Social Transformation at Chaco Canyon', Cambridge Archaeological Journal, 18 (2008), 70-78.

${ }^{41}$ James Fentress and Chris Wickham, Social Memory (Oxford: Blackwell, 1992). 


\section{Scale Change}

The view of scale as socially produced has the further advantage of highlighting its dynamic character: while many social processes do not involve scale change, scale change can hardly happen without profound societal transformations. To take just one very obvious dimension of human societies, changes in the scale of political systems - whether scale growth (like the westward expansion of the United States or the making of the European Union), or fragmentation (like the ending of the Roman Empire or the fall of the Soviet block) can be seen as 'spaces of opportunity'. Old forms of articulation become obsolete while new ones emerge and, as they do so, they become new potential resources for human actors, who can use them for entirely different purposes, depending on their aims, capabilities, and operational scales.

Scale change is particularly important in the study of distant historical periods on which the information available is scarce and irregular. In many cases, describing in detail the different scales of social articulation will be a difficult task, while scale change - especially if relatively sudden - tends to show more prominently, nonetheless, because it is often linked to perceivable changes in the nature and/or visibility of our evidence: the interruption of written records or their emergence, a drop or rise in the monumentality and/or sophistication of material culture, and so on. Scale change can be an indicator of social change, and changes (increase or decrease) in spatial scale are often especially visible. Their power to reveal underlying social processes and possibilities open or lost thereafter is great. On the other hand, by detecting cases in which the spatial or the temporal dimensions of scale change are clearly perceivable to local actors, it is possible to address the difficult issue of bottom-up agency. In most early historical societies, the available evidence tends to enhance the visibility of power-wielding individuals and groups and their deeds while obscuring the lower social layers. This has frequently led historians to build views of the past dominated by top-down agency, in which social structures are conceived as the creation of powerful actors. Close consideration of contexts in which the lower social strata - or segments thereof - are able to perceive and react to scale change can help build an image of bottom-up proactive social agency richer than the standard, narrower model: top-down action by the powerful, acceptance or resistance by the lower social layers. 


\section{Hidden Scales}

Back in 1978, when Gerald Berreman complained about how little attention scale had received thitherto in anthropology and other social sciences, Raoul Naroll cried foul: scale in fact had been addressed by many authors, only they did not use the word scale, but other terms such as cultural evolution or societal complexity, although 'even a cursory review of these hologeistic studies of cultural evolution reveals that scale is precisely what they are about'. ${ }^{42}$ If this was true of sociology or anthropology in the 1970s, it is much more so of history, where - by contrast with archaeology - the interest in theory tends to be rather modest ${ }^{43}$ It is easy to detect a number of topics with strong connections to scale issues that remain mostly unconnected to scale and other associated notions because of lack of a higher-level comprehensive framework, even if, echoing Naroll, scale and scale change is precisely what they are about. Historical research during the last decades has been influenced by the global historical processes that the present generation is living through, of which scale, and the interactions between scale levels, are major components. For example, in the 1980s and 1990s the collapse of great political powers became a major study subject in the context of the ending of the Cold War and the fall of the Soviet block. As the history of the fragmenting Soviet Union was thoroughly reassessed, scholars turned to the United States seeking signs of similar processes that could eventually lead to an abrupt ending of American world hegemony, and the same atmosphere triggered a wave of research on models of sudden fragmentation of large-scale polities across a wider chronological span. ${ }^{44}$ This field has been more recently revived by growing social concerns about environmental threats, with the adoption of the notions of resilience (a physical concept describing a system's capability to undergo change

\footnotetext{
${ }^{42}$ Berreman, 'Scale and Social Relations'; Raoul Naroll, 'More on Scale and Social Relations', Current Anthropology, 20 (1979), 187.

43 Patrick Joyce, 'The Return of History: Postmodernism and the Politics of Academic History in Britain', Past and Present, 158 (1998), 207-35.

${ }^{44}$ Paul Kennedy, The Rise and Fall of the Great Powers: Economic Change and Military Conflict From 1500 to 2000 (New York: Random House, 1987); Joseph A. Tainter, The Collapse of Complex Societies (Cambridge: Cambridge University Press, 1988); Colin Renfrew, 'Systems Collapse as Social Transformation', in Approaches to Social Archaeology, ed. by Colin Renfrew (Edinburgh: Edinburgh University Press, 1984), pp. 366-89.
} 
without losing its identity) and regeneration (the reconstruction of complex systems after periods of collapse and/or fragmentation). ${ }^{45}$

But more than collapse, it is the growth of large-scale systems that has mainly attracted scholarly attention. Ever since the Cold War period, the study of supranational articulations has become a major field of experimentation with models like core-periphery, dependency theory, or the world-systems perspective popularized by Wallerstein. ${ }^{46}$ The latter is especially revealing, since it started as a debate on the emergence of complex systems of supra-national hegemonies over the last five hundred years, but quickly expanded to encompass all of human history. ${ }^{47}$ Perhaps because of their predominant interest in large-scale articulations of the present and the recent past, some of those developments seem to have been engulfed by the broader wave of globalization studies. ${ }^{48}$ However, globalization too, like world-systems theory before, has evolved from a strictly contemporary initial focus to a wider temporal span, whether by studying the long-term processes that made globalization possible ${ }^{49}$ or by analysing similar

${ }^{45}$ After Collapse: The Regeneration of Complex Societies, ed. by Glenn M. Schwartz and John J. Nichols (Tucson: University of Arizona Press, 2006); Nick Abel, David H. M. Cumming, and John M. Anderies, 'Collapse and Reorganization in Social-Ecological Systems: Questions, Some Ideas, and Policy Implications', Ecology and Society, 11.1 (2006), 17, <http://www.ecologyandsociety .org/vol1 1/iss1/art17/> [accessed 26 July 2010]; Graeme S. Cumming and John Collier, 'Change and Identity in Complex Systems', Ecology and Society, 10.1 (2005), 29, <http://www.ecologyand society.org/vol10/iss1/art29/> [accessed 26 July 2010]; Ian Morris, 'The Collapse and Regeneration of Complex Society in Greece, 1500-500 BC', Princeton/Stanford Working Papers in Classics, Stanford University, Version 1.0, December 2005, <http://papers. ssrn.com/sol3/ papers.cfm ?abstract_id=1426834> [accessed 26 July 2010]; Kathleen D. Morrison, 'All Is Not Lost when the Center Does Not Hold', Science, 315 (2007), 42-43.

${ }^{46}$ Immanuel Wallerstein, The Modern World-System, I: Capitalist Agriculture and the Origins of the European World-Economy in the Sixteenth Century (New York: Academic Press, 1974); Wallerstein, The Modern World-System, II: Mercantilism and the Consolidation of the European World-Economy, 1600-1750 (New York: Academic Press, 1980).

${ }^{47}$ The World System: Five Hundred Years or Five Thousand?, ed. by Andre Gunder Frank and Barry K. Gills (London: Routledge, 1993); Thomas D. Hall, 'World-Systems and Evolution: An Appraisal', Journal of World-Systems Research, 2.4 (1996), <http://jwsr.ucr.edu/archive/vol2/ v2_n4.php> [accessed 26 July 2010].

${ }^{48}$ Christopher Chase-Dunn, 'Globalization: A World-Systems Perspective',Journal of WorldSystems Research, 5.2 (1999), 187-215, <http://jwsr.ucr.edu/archive/vol5/number2/v5n2_split /jwsr_v5n2_chase-dunn.pdf > [accessed 26 July 2010].

${ }^{49}$ Sassen, Territory, Authority and Rights. 
processes of large-scale articulation in the past which, though working on a lessthan-global scale, pose similar theoretical problems. ${ }^{50}$

\section{Studying Scale and Scale Change in the Early Middle Ages}

Collapse, world-systems, globalization, and the like are primarily oriented to the largest possible scale: supra-national, regional, or global articulations. It is hardly surprising that among specialists of earlier historical periods, those that work on very large entities, like empires, have been relatively more interested in linking to them. Comparative studies have thus benefited from discovering common grounds for the combined analysis of temporally and spatially separate imperial phenomena. ${ }^{51}$ By contrast, the European Middle Ages seem to find little room in such studies, except perhaps for the late medieval origins of the European trade expansion and empire formation. ${ }^{52}$ The early Middle Ages are much detached from such debates, whether because early medievalists have relatively little regard for global and present-day issues, or because scholars working on the latter often feel that they have done enough by extending their scope to the fifteenth century. Yet, any thought that there is no room for medieval issues in the global debates is firmly contradicted by the way in which a significant number of prehistorians much more interested in interdisciplinary theoretical issues - have managed to join in, even if the very small-scale societies they normally study would look at first sight most inappropriate to those approaches. In fact, a number of major issues of discussion among prehistorians, such as the emergence of social inequality and the state or the impact of the Mediterranean long-distance trade networks upon their proto-historic peripheries, can be fruitfully connected to longer spanning visions of historical global developments. ${ }^{53}$ In the end it seems that by adopting compati-

${ }^{50}$ Richard Hingley, 'Recreating Coherence without Reinventing Romanization', Digressus, Suppl. 1 (2003), 111-19; María José Hidalgo, 'Algunas reflexiones sobre los límites del oekoumene en el Imperio Romano', Gerion, 23 (2005), 271-85.

${ }^{51}$ Empires: Perspectives from Archaeology and History, ed. by Susan E. Alcock and others (Cambridge: Cambridge University Press, 2001); Kathleen D. Morrison, 'All Is Not Lost'.

${ }^{52}$ A different approach in Sassen, Territory, Authority and Rights, who compares the present emergence of global assemblages to the late medieval roots of the national state, the kind of assemblage out of which globalization is born.

${ }^{53}$ Peter S. Wells, Farms, Villages and Cities: Commerce and Urban Origins in Late Prehistoric Europe (Ithaca: Cornell University Press, 1984); Wells, 'Production Within and Beyond Imperial Boundaries: Goods, Exchange and Power in Roman Europe', in World-Systems Theory in 
ble conceptual frameworks, scholars with a theoretical concern are more able to make their research relevant to their colleagues from other fields, and vice versa. ${ }^{54}$

The starting point of this book - and of the research project it stems from is that the European early Middle Ages constitute a very suitable laboratory for the study of scale issues. In fact, most of the key concepts discussed above can be put to use in an early medieval context. A major advantage of the period is that, when changes in social complexity across its entire temporal and spatial scalerange are considered, it includes an excitingly complex combination of both sides of scale change: fragmentation and growth. In its simplest formulation, the early medieval period can be explained as the collapse of the very complex Roman articulation, followed by deep fragmentation and the slow emergence of entirely new, larger scale medieval entities. This would be enough to bring in concepts such as collapse, resilience, emergence, or regeneration, but it would also probably mean wasting most of the explanatory potentiality of a scale-based approach. The greatest richness of the early Middle Ages resides in its diversity: every region in post-Roman Europe fragmented at a different pace and/or degree from the next one and the ensuing articulation of larger systems started at different times and reached different levels from one to the other, yet there were significant mutual interactions and influences among them in the process. ${ }^{55}$

Never before Rome did a political system of comparable scale exist in Europe. The mere hugeness of the upper systemic level created much ground for the emergence of intermediate ones which did not exist before either: Hispania, Gallia, or Britannia, as territorial constructs were a consequence of the Roman domination, like the notion of municipium also was, at a lesser territorial level. Within the overall framework, regional development was mainly a matter of diversity. Not all areas were similarly integrated and the critical issue of how much each region's economy and social structures depended on the Roman state and the smooth operation of its large-scale articulations is increasingly seen as key in understanding the post-Roman period. ${ }^{56}$ Since the operating presence of the Imperial

Practice: Leadership, Production and Exchange, ed. by P.Nick Kardulias (New York: Rowman and Littlefield, 1999), pp. 85-101.

${ }^{54}$ See Reynolds, this volume.

${ }^{55}$ See Fernández Mier, this volume.

${ }^{56}$ Simon Esmonde Cleary, The Ending of Roman Britain (London: Batsford, 1989); Julio Escalona, 'Patrones de fragmentación territorial: el fin del mundo romano en la meseta del Duero', in Comunidades locales y dinámicas de poder en el norte de la Peninsula Ibérica durante la Antigüedad Tardia, ed. by Urbano Espinosa and Santiago Castellanos (Logroño: Instituto de 
state was a major factor in providing an inclusive cultural background, and in keeping together extensive territories and the links between them, it is hardly surprising that, after Rome's demise, an enormously diverse situation should set in.

Within a scale-based perspective, in the event of a collapse at the highest complexity level, the next issue is how can this affect the underlying components and how far will fragmentation go. The answers to those questions, of course, differ regionally in a post-Roman context. Fragmentation processes took place at different intensity and velocity: different territorial scales, different social and economic structures, sometimes different languages, different histories. Some areas sunk into fragmentation levels comparable to those of the pre-Roman period, while in others the provincial society managed to structure itself at a middle scale of some internal complexity, whether by recycling former middlelevels of the Roman period or creating totally new ones. The lack of the upper layer triggered divergent trajectories, and the scale of each outcome appears as a fine indicator not only of its degree of internal articulation, but also of its degree of dependence from the Imperial system as a whole.

Seeing the post-Roman west as a paramount case of multi-level scale change helps realize the narrowness of standard approaches based upon the continuity/ rupture debate, as denounced recently by Chris Wickham. Post-Roman Europe is not a simple lapse into small-scale structuration. The Roman Empire ended, but Rome loomed long on the early Middle Ages. A number of pervasive cultural elements, such as the historical memory of the Roman Empire and its legal/ political legacy, the use of Latin or the influence of a common religion and Church structure were recycled into the new mental landscape, providing an allencompassing cultural upper layer, even in the absence of political or economic structures at a similar scale. Christianity as a major ideological unifying factor, as well as the capacity of some barbarian kingdoms to present themselves as recreations of Rome, for example, have paved the path for continuity models, while military stress, disrupted patterns of landownership, urban decline or waning material culture are the traditional components of discontinuity.

Partial approaches have much to do with this pseudo-debate. ${ }^{57}$ It is the scholars' tendency to overlook the broader framework and let one or another

Estudios Riojanos, 2006), pp. 165-99. The discussion of continuity vs disruption in Chris Wickham, Framing the Early Middle Ages (Oxford: Oxford University Press, 2005), pp. 10-14, is the most serious attempt so far to supersede this sterile pseudo-debate.

${ }^{57}$ Wickham, Framing, p. 2. 
thematic thread or regional case take the leading role in shaping their overall conceptions of the period that has paved the path for continuist or rupturist rigid views, ultimately unable to talk to each other. It may be useful at this point to recall Levin's remark that 'the problem is not to choose the correct scale of description, but rather to recognize that change is taking place on many scales at the same time, and that it is the interaction among phenomena on different scales that must occupy our attention'. ${ }^{58}$ In other words, we need to consider the large and the small, and everything in between: we may choose to study villages in a certain area, but it makes a critical difference whether in this social system the village is the highest possible scale or whether there are many higher-level ones. Our chances of recognizing the global in the local and vice versa depend much on this. ${ }^{59}$

Early medieval scale growth is also a good benchmark for scale-based approaches. ${ }^{60}$ Most areas across Western Europe seem to have reached their respective fragmentation peaks during the early medieval period, and most of them initiated afterwards a phase of scale growth, converging in to larger, more complex entities. However, the intensity and duration of fragmentation differed much from one case to another, and the pace and degree of growth was also much diverse. For example, in southern Britain, sub-Roman fragmentation was very intense, but small polities began to coalesce into larger ones by the end of the seventh century and political centralization was a powerful trend in the eighth. ${ }^{61}$ Fragmentation in north-western Iberia, by contrast, started with similar intensity, but was somehow held back by the emergence of the Visigothic state in the late sixth century. Inclusion in such a large-scale political system did not reverse the

\footnotetext{
${ }^{58}$ Levin, 'The Problem of Pattern and Scale', p. 1947.

59 'The key to understanding how information is transferred across scales is to determine what information is preserved and what information is lost as one moves from one scale to the other' (Levin, 'The Problem of Pattern and Scale', p. 1950).

${ }^{60}$ The debate between the view of early medieval economic growth as a result of the intensification of agricultural production within local communities - mainly advocated by G. Duby - and the opinion of those who - like Richard Hodges - give priority to long-distance, elite-driven exchange is to a great extent a matter of conflicting scales of analysis and discourse, as recently suggested by John Soderberg, 'Distinguishing the Local from the Regional: Irish Perspectives on Urbanization in Early Medieval Europe', in Exploring the Role of Analytical Scale in Archaeological Interpretation, ed. by James R. Mathieu and Rachel E. Scott, British Archaeological Reports, International Series, 1261 (Oxford: Barhedges, 2004), pp. 67-82.

${ }^{61}$ Stephen R. Bassett, 'In Search of the Origins of Anglo-Saxon Kingdoms', in The Origins of AngloSaxon Kingdoms, ed. by Stephen R. Bassett (Leicester: Leicester University Press, 1989), pp. 3-52.
} 
process, but contained it until the collapse of the kingdom of Toledo, following which most of north-western Iberia slipped in to a fragmentation comparable to that of sub-Roman Britain. ${ }^{62}$ Within the general fragmentation-convergence curve, therefore, Iberia presents two fragmentation peaks (mid-fifth and mideighth centuries) and a generally slower process of state formation, while Britain shows sudden, acute collapse followed by a precocious and intense convergence into large-scale structuration. In neither case - as in the rest of the European regions - was a scale comparable to that of Rome's heyday ever reconstructed with some durability. This could be a good case for testing the notions of resilience and regeneration after collapse. Despite the weight of the Roman legacy, we can wonder to what extent claims to the restoration of the Roman order are more than rhetorical recycling, by contrast with the kind of socially pervasive political identity that can be spotted in, say, the Egyptian middle kingdom. ${ }^{63}$

The mechanisms of early medieval scale-growth varied much depending on how intense the previous fragmentation was. Within a general trend towards state formation and increasing social inequality, the starting conditions differed much regionally. However if we compare the kind of articulation processes addressed by world-systems or globalization specialists and those studied by prehistorians, the early Middle Ages look definitively closer to the latter. The main difference is that the amount and quality of the evidence - not least the written evidence - supersedes by far the late prehistoric record, and makes it possible to formulate questions that are nearly intractable for earlier periods. Agency and scale jumping, for example, when built into a scale approach, are fundamental in connecting micro and macro analysis, and in bridging the individual and the structural. They can greatly help supersede the dominant approach that stresses top-down action by elites as the one that really 'creates structure', while ordinary people remain the passive victims of large-scale developments or are granted limited agency, normally formulated as 'resistence'. The growing body of settlement archaeology, combined with renewed readings of the texts, allows instead for an alternative view focussed upon the role of small-scale or local actors and proactive bottom-up agency in those processes, that is, the construction of higher scales by actors from lower scales. ${ }^{64} \mathrm{~A}$ large number of social processes can be

\footnotetext{
${ }^{62}$ Santiago Castellanos and Iñaki Martín Viso, 'The Local Articulation of Central Power in the North of the Iberian Peninsula (500-1000)', Early Medieval Europe, 13 (2005), 1-42.

${ }^{63}$ John Moreland, 'The Carolingian Empire: Rome Reborn?', in Empires, ed. by Alcock and others, pp. 392-418.

${ }^{64}$ Carla Sinopoli, 'Imperial Integration and Imperial Subjects', in Empires, ed. by Alcock and others, pp. 195-200. A comparable approach is used by Daniel Lord Smail, The Consumption of
} 
enriched in this vein. For example, the Roman municipium is certainly a creation from the overall system, but its specific implementation in many areas across the empire is now increasingly seen as a result of proactive agency by local notables. Early medieval overkingship may result from imposition by force of a bullying lord's rule, but it may just as well be a power device developed by lesser rulers to advance their positions and resources. It seems that two elements may be worth investigating in this respect: a) the presence of intermediate agents (local notables, sub-kings, medium-scale aristocracies) who may operate simultaneously as members of structures at more than one scale; b) the capacity of those petty leaders to keep control of the higher structures they create. An interesting example - fully extrapolatable to early medieval contexts - may be E. Boehm's discussion of egalitarian ideology as a limiter to rulership, formulated by him as 'reverse dominance'. ${ }^{65}$

Finally, the notions of scale and scale change must be seen as a tool for comparison, because of their relational nature. Much historical research consists in comparing. Comparing whole social systems one to another, or specific levels within them, or perhaps specific thematic strands, like trade or coinage. More often than not, our historical or archaeological evidence will be handled by comparing diachronic situations and detecting changes across a time span. Social scientists can select the variables they see as crucial and collect the relevant information to process. Historians and archaeologists largely depend on whatever evidence is available for one given time and area. Cross comparison in their case will require the combination of different kinds of evidence and then the building of an explanation of why and how those distinct sources can be brought to illuminate the same problem. ${ }^{6}$ In this process, scale awareness is a paramount factor in sound modelling. ${ }^{67}$

Summing up, bringing scale analysis into early medieval studies may yield two different kinds of benefits. On the one hand, fragmentation and lack of communi-

Justice: Emotions, Publicity and Legal Culture in Marseille, 1264-1423 (Ithaca: Cornell University Press, 2003), to describe bottom-up agency in the creation of a late medieval legal culture. I thank Isabel Alfonso for bringing this title to my attention. See also Escalona and Reyes, this volume.

${ }^{65}$ Christopher Boehm, 'Egalitarian Behavior and Reverse Dominance Hierarchy', Current Anthropology, 34 (1993), 227-54.

${ }^{66}$ See Chris Wickham, 'Sul mutamento sociale ed economico di lungo periodo in Occidente (400-800)', Storica, 23 (2002), 7-27 and especially Wickham, 'Problems of Comparing Rural Societies in Early Medieval Western Europe', Transactions of the Royal Historical Society, 6th ser., 2 (1992), 221-46.

${ }^{67}$ See Reynolds, this volume. 
cation among early medievalists have long hampered the emergence of research at an international level. This derives as much from the regional specificities of our evidence as from the lack of, or disregard for, a high-level theoretical framework. Low-level, ad hoc models such as 'rise and fall' or 'change or continuity' have only widened the gap. By contrast the rich theoretical tools built around the notion of scale by different social sciences, when applied to the early Middle Ages, have the power of providing an abstract all-encompassing theoretical framework in which to situate an otherwise extremely fragmented field of study. On the other hand, there is nowadays a critical need of intercommunication between history and the social sciences, which cannot limit itself to importing methods or concepts from the social sciences into history with the hope that historical research will improve from it and 'total theory' à la Annales will eventually emerge out of the blue. In order to dialogue with the social sciences, historians should try to contribute to the construction of meaningful theoretical frameworks and engage in the sort of debates that can make historical research relevant in a wider context. Experimenting with scale and scale change may be just one possible move in this direction. 